ARTIGO ORIGINAL

\title{
Propriedades energéticas da biomassa de Acacia mearnsii De Wild. em diferentes idades e locais de cultivo
}

\author{
Energy properties of the biomass of Acacia mearnsii De Wild. in differents \\ ages and sites of cultivation
}

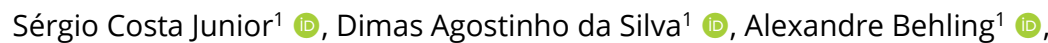 \\ Henrique Soares Koehler ${ }^{1}$ (D), Augusto Arlindo Simon² ${ }^{(D)}$, Athina Costa ${ }^{1}$ (D) \\ ${ }^{1}$ Universidade Federal do Paraná - UFPR, Curitiba, PR, Brasil \\ ${ }^{2}$ Tanagro S/A. Montenegro, RS, Brasil
}

Como citar: Costa Junior, S., Silva, D. A., Behling, A., Koehler, H. S., Simon, A. A., \& Costa, A. (2021). Propriedades energéticas da biomassa de Acacia mearnsii De Wild. em diferentes idades e locais de cultivo. Scientia Forestalis, 49(131), e3406. https://doi.org/10.18671/scifor.v49n131.04

\begin{abstract}
Resumo
A qualidade da biomassa utilizada como matéria prima na geração de energia depende de propriedades como: densidade básica, poder calorífico superior, teor de materiais voláteis, carbono fixo e cinzas. Assim, o objetivo dessa pesquisa foi avaliar o efeito do local de cultivo e da idade, bem como sua interação, sobre tais propriedades da biomassa de árvores de Acacia mearnsii. Com o propósito de alcançar o objetivo foram amostrados aleatoriamente povoamentos comerciais da espécie em quatro idades e em três locais de cultivo. Cada indivíduo teve sua biomassa separada em copa e fuste para determinação das variáveis energéticas em laboratório, assim como a biomassa total. Para copa e fuste os valores de densidade básica variaram entre 0,422 e $0,581 \mathrm{~g} \mathrm{~cm}^{-3}$, de materiais voláteis entre 69,09 e $78,27 \%$, de carbono fixo entre 20,94 e $27,68 \%$, de cinza entre 0,73 e 3,80\%, e poder calorífico superior entre 4.518 e $5.089 \mathrm{kcal} \mathrm{kg}^{-1}$. As propriedades energéticas da biomassa tanto de copa como de fuste foram influenciadas pelo local de cultivo e a idade dos povoamentos. A interação entre os fatores foi significativa para a maioria das variáveis. A biomassa de todos os povoamentos pode ser utilizada para fins energéticos, no entanto, a dos povoamentos mais velhos são mais apropriadas.
\end{abstract}

Palavras-chave: Acácia negra; Qualidade energética; Componentes da biomassa; Bioenergia.

\begin{abstract}
The quality of biomass used as raw material in energy generation depends on properties such as: basic density, gross calorific value, volatile matter content, fixed carbon and ashes. Thus, the objective of this research was to evaluate the effect of cultivation site and age, as well as their interactions, on such properties of Acacia mearnsii tree biomass. In order to reach the objective, commercial stands of the species were randomly sampled at four ages and at three cultivation sites. Each individual had its biomass separated in crown and stem to determine the energy variables in the laboratory, as well as the total biomass. For crown and stem the basic density values ranged from 0.44 to $0.58 \mathrm{~g} \mathrm{~cm}^{-3}$, from volatile materials between 69.09 and $77.55 \%$, from fixed carbon between 21.54 and $27.68 \%$, from gray between 0.73 and $3.80 \%$ and gross calorific value between 4,518 and $5,089 \mathrm{kcal} \mathrm{kg}^{-1}$. The energy properties of both crown and stem biomass were influenced by the cultivation site and the age of the stands. The interaction between the factors was significant for most variables. Biomass from all stands can be used for energy purposes, however, older stands are more appropriate.
\end{abstract}

Keywords: Black wattle; Energy quality; Biomass components; Bioenergy.

Fonte de financiamento: Conselho Nacional de Desenvolvimento Científico e Tecnológico (CNPq) e Coordenação de Aperfeiçoamento de Pessoal de Níve Superior (CAPES - Código de financiamento 001).

Conflito de interesse: Nada a declarar.

Autor correspondente: o.sergio.costa@gmail.com

Recebido: 14 junho 2019.

Aceito: 23 novembro 2020.

Editor: Paulo Henrique Müller Silva.

(c) Este é um artigo publicado em acesso aberto (Open Access) sob a licença Creative Commons Attribution, que permite uso, distribuição e reprodução em qualquer meio, sem restrições desde que o trabalho original seja corretamente citado. 


\section{INTRODUÇÃO}

Dentre as espécies dendrocombustíveis cultivados no Brasil se destacam as dos gêneros Acacia e Eucalyptus. A acácia-negra é uma espécie com um rápido crescimento com taxas de IMA de 3,34 t.ha.ano-1 e 11,22 t.ha.ano ${ }^{-1}$ em biomassa de copa e fuste respectivamente. A acácia-negra é uma espécie com um rápido crescimento cultivada comercialmente em rotações de 7 a 10 anos gerando múltiplos produtos de interesse comercial. Por exemplo, a casca é matéria prima para a extração do tanino (Simon, 2005), a madeira é utilizada na produção de celulose e papel como lenha e carvão e recentemente na produção de pellets. Contudo, ainda há a biomassa de copa (galhos e folhas) que pode ser utilizada na geração de energia.

Por essa razão, a importância em conhecer a produção de biomassa em cada um de seus componentes (copa e fuste). Diversos estudos abordam temas relacionados aos estoques de biomassa, em se tratando da acácia-negra (Acacia mearnsii De Wild.), destacam-se os trabalhos de Costa Junior et al. (2018) e Sanquetta et al. (2014). No entanto, quando se trata do uso de biomassa para gerar energia, além dos estoques de biomassa são importantes as questões relacionadas com a qualidade.

As propriedades energéticas de uma biomassa permitem avaliar sua qualidade para o uso na geração de energia. Nesse sentido, se destaca o trabalho de Silva et al. (2017) que analisa o potencial dendroenergético dos componentes da biomassa de acácia-negra e o estudo de Eloy et al. (2017) que avalia o efeito da idade e do espaçamento de plantio sobre as propriedades energéticas da espécie.

Os efeitos causados pela idade e local de cultivo sobre às propriedades energéticas da biomassa de diferentes espécies vêm sendo estudados a algum tempo. Por exemplo, Kumar et al. (2011), estudando híbridos de Eucalyptus, constataram que os teores de cinzas e de carbono fixo tendem a reduzir com a maturidade da árvore, enquanto que a densidade, o poder calorífico e os materiais voláteis tendem a aumentar. Para Soares et al. (2015), isso provavelmente está atrelado as alterações fisiológicas da árvore que ocorrem ao longo do tempo.

Carneiro et al. (2017), verificaram a influência de fatores como sítio sobre a qualidade da madeira de clones de Eucalyptus para fins energéticos. De acordo com Oliveira et al. (2012) as condições ambientais influenciam as atividades cambiais de formação da madeira e sua anatomia. Para Gonçalves et al. (2004) a disponibilidade de luz, pluviosidade e temperatura causam efeitos significativos na formação da madeira.

No entanto, não há trabalhos específicos que considerem o efeito da interação entre a idade e o local de cultivo sobre as propriedades energéticas dos componentes da biomassa de acácia-negra. Assim, considerando que a idade influencia significativamente as variáveis energéticas (Eloy et al., 2017), assim como o local, propôs-se como objetivo avaliar o efeito dos fatores local e idade, bem como a interação entre eles, sobre as propriedades energéticas dos componentes da biomassa de árvores de Acacia mearnsii.

\section{MATERIAIS E MÉTODOS}

\section{Amostragem dos povoamentos}

Para o desenvolvimento desta pesquisa foram avaliados 12 povoamentos comerciais de acácia-negra (Acacia mearnsii De Wild.) no estado do Rio Grande do Sul. $\mathrm{Na}$ implantação dos mesmos foram adotadas práticas de cultivo mínimo, com uma subsolagem a 40 centímetros de profundidade e duas gradagens na linha de plantio. As mudas utilizadas foram produzidas a partir de sementes oriundas de áreas de produção de sementes da empresa TANAGRO S.A. Cada muda recebeu 75 gramas de adubo organo-mineral 4-12-8. O espaçamento adotado foi de $3 \mathrm{~m}$ entre linhas e 1,75 m entre plantas na linha. Todos os povoamentos foram submetidos às mesmas condições de manejo. 
A pesquisa consistiu em instalar um experimento com 48 unidades amostrais, constituídas de uma parcela circular com área de 78,54 m², aproximadamente $3.800 \mathrm{~m}^{2}$, amostrados de forma aleatória. Foram amostrados povoamentos em três regiões, denominadas: Cristal, Encruzilhada do Sul e Piratini. Em cada região foram amostrados quatro povoamentos de modo a abranger toda a rotação da cultura. Quatro unidades amostrais foram instaladas em cada povoamento, que foram agrupadas de acordo com o estádio de desenvolvimento originando classes de idade. Ao todo 699 árvores foram amostradas (Tabela 1).

Tabela 1: Idade qualitativa, classificação dos solos e média das variáveis meteorológicas: precipitação, temperatura máxima, temperatura média, temperatura mínima e umidade relativa do ar, para os períodos de crescimento dos povoamentos de Acacia mearnsii amostrados no estado do Rio Grande do Sul.

\begin{tabular}{|c|c|c|c|c|c|c|c|c|c|}
\hline Local & $\begin{array}{l}\text { Idade } \\
\text { (anos) }\end{array}$ & $\begin{array}{c}\text { Idade } \\
\text { (qualitativa) }\end{array}$ & $\mathbf{N}^{0}$ & Solo & $\begin{array}{c}\text { PP } \\
(\mathrm{mm})\end{array}$ & $\begin{array}{l}\text { Tmáx. } \\
\left({ }^{\circ} \mathrm{C}\right)\end{array}$ & $\begin{array}{l}\text { Tméd. } \\
\left({ }^{\circ} \mathrm{C}\right)\end{array}$ & $\begin{array}{l}\text { Tmin. } \\
\left({ }^{\circ} \mathrm{C}\right)\end{array}$ & UR (\%) \\
\hline \multirow{4}{*}{ Cristal } & 1,75 & Jovem & 59 & PVA & 1.448 & 23,8 & 18,4 & 14,3 & 82,11 \\
\hline & 2,75 & Média Inicial & 49 & PBAC & 1.271 & 23,9 & 18,2 & 14,0 & 81,69 \\
\hline & 5 & $\begin{array}{c}\text { Média } \\
\text { Avançada }\end{array}$ & 44 & PBAC & 1.326 & 23,3 & 17,9 & 13,8 & 82,10 \\
\hline & 10 & Madura & 60 & PVAd & 1.251 & 23,4 & 17,9 & 13,8 & 81,80 \\
\hline \multirow{4}{*}{$\begin{array}{l}\text { Encruzilhada } \\
\text { do Sul }\end{array}$} & 1,83 & Jovem & 58 & $\mathrm{RRd}$ & 1.028 & 23,0 & 17,2 & 13,1 & 75,60 \\
\hline & 3,08 & Média Inicial & 69 & SXe & 1.113 & 22,8 & 16,8 & 12,7 & 74,81 \\
\hline & 5,75 & $\begin{array}{c}\text { Média } \\
\text { Avançada }\end{array}$ & 52 & PVAe & 1.354 & 23,4 & 17,5 & 13,4 & 75,66 \\
\hline & 10,75 & Madura & 71 & $\mathrm{RRd}$ & 1.415 & 23,4 & 17,5 & 13,5 & 75,44 \\
\hline \multirow{4}{*}{ Piratini } & 1 & Jovem & 73 & $\mathrm{RL}$ & 1.697 & 23,4 & 18,2 & 14,3 & 83,37 \\
\hline & 2,33 & Média Inicial & 48 & PVAd & 1.237 & 23,3 & 17,8 & 13,6 & 81,79 \\
\hline & 5,25 & $\begin{array}{c}\text { Média } \\
\text { Avançada }\end{array}$ & 62 & PVAd & 1.316 & 23,2 & 17,7 & 13,6 & 82,18 \\
\hline & 9,83 & Madura & 54 & $\mathrm{RL}$ & 1.266 & 23,5 & 18,0 & 13,9 & 81,76 \\
\hline
\end{tabular}

Em que PP: precipitação em $(\mathrm{mm})$; Tmáx.: temperatura máxima em $\left({ }^{\circ} \mathrm{C}\right)$; Tméd.: temperatura média em $\left({ }^{\circ} \mathrm{C}\right)$; Tmin.: a temperatura mínima em $\left({ }^{\circ} \mathrm{C}\right)$; UR: umidade relativa do ar em (\%); PVA: Argissolo Vermelho-Amarelo; PBAC: Argissolo Bruno-Acizentado; PVAd: Argissolo Vermelho Amarelo Distrófico; RRd: Neossolos Regolítico Distrófico; SXe: Planossolo Háplico Eutrófico; PVAe: Argissolo Vermelho-Amarelo Eutrófico; RL: Neossolo Litolítico.

\section{Variáveis mensuradas}

As árvores presentes nas parcelas foram derrubadas e mensuradas quanto a circunferência à altura do peito (cap), a altura total (h) e a biomassa do componente fuste (madeira do fuste principal e casca) e da copa (galhos vivos e mortos, folhas, flores e frutos). Desses indivíduos foram coletadas amostras de cada componente. Da copa, uma amostra com aproximadamente $1.500 \mathrm{~g}$ foi tomada ao longo do comprimento total da copa nas posições de $0 \%$ (inserção do primeiro galho vivo), 25\%, 50\%, 75\% e 95\%. Para o fuste, foram retirados cinco discos de aproximadamente $2 \mathrm{~cm}$ de espessura nas posições: 0\% (nível do solo), $25 \%, 50 \%, 75 \%$ e $95 \%$ em relação à altura total.

Os discos do fuste foram divididos em 4 partes, das quais, duas em sentidos opostos foram utilizadas para a determinação da densidade básica, as demais foram misturadas originando uma amostra composta que foi utilizada paras as demais análises. As amostras foram reduzidas manualmente, em seguida processadas em moinhos de faca, e secas em estufas de circulação e renovação de ar.

As propriedades energéticas da biomassa de cada componente foram obtidas a partir das seguintes variáveis: densidade básica, teor de materiais voláteis, teor de carbono fixo, teor de cinzas e poder calorífico superior. Todas as análises foram realizadas com amostras de 
biomassa de cada componente. Para tanto, foi utilizado o Laboratório de Energia de Biomassa Florestal da Universidade Federal do Paraná.

Para a determinação da densidade básica procedeu-se de acordo com a norma técnica da American Society for Testing Materials ASTM D2395 (American Society for Testing Materials, 2001). Para determinação dos teores de materiais voláteis, carbono fixo e cinzas foi utilizada a metodologia estabelecida pela norma técnica ASTM D1762-84 (American Society for Testing Materials, 2013a). Para a determinação do poder calorífico superior utilizou-se uma bomba calorimétrica digital modelo C5000 Cooling System IKA WORKS, seguindo os procedimentos estabelecidos na norma técnica ASTM D5865 (American Society for Testing Materials, 2013b).

\section{Análises estatísticas}

Com a finalidade de estudar as propriedades energéticas das árvores de acácianegra em povoamentos com diferentes idades e em diferentes locais de cultivo, foi calculada a média das variáveis densidade básica, teor de materiais voláteis, carbono fixo, cinzas e poder calorífico superior para os componentes de cada unidade amostral composta por quatro repetições. Foram considerados os componentes copa, fuste e total (copa + fuste).

As médias e os intervalos de confiança das variáveis densidade básica, teor de materiais voláteis, carbono fixo, cinzas e poder calorífico superior referente a copa e ao fuste foram calculados a partir de valores mensurados diretamente em porções das amostras coletadas. Em relação ao total (copa + fuste), a mesma foi estimada por meio da média ponderada das variáveis de cada componente pela sua biomassa.

Todas as variáveis foram comparadas por meio da análise de variância, valendo-se do modelo do delineamento inteiramente casualizado. O conjunto de tratamentos foi arranjado em um fatorial ( $3 \times 4)$ a fim de testar a interação entre os fatores (idade e local) e também os efeitos principais. Foi aplicado o teste de Bartlett e de Shapiro-Wilk afim de verificar a homogeneidade da variância e a normalidade dos dados, respectivamente. Constatada a rejeição da hipótese da nulidade pela análise de variância foi aplicado o teste de Tukey para discriminar as médias. Todas as análises foram realizadas a 0,05 de significância.

A análise de variância para o teor de cinzas do fuste e do total foi conduzida com valores transformados, aos quais foi aplicado logaritmo na base 10 , uma vez que os testes aplicados para avaliar a homogeneidade das variâncias e também normalidade dos resíduos foram significantes.

\section{RESULTADOS E DISCUSSÕES}

\section{Densidade básica}

As maiores médias para a densidade básica dos galhos, fuste e total foram observadas nos povoamentos em idade madura, ou seja, há uma tendência de aumento nos valores de densidade básica à medida que a idade aumenta (Figura 1A, 1B e 1C). Sanquetta et al. (2013) estudando Acacia mearnsii constataram a mesma tendência de aumento da densidade básica com a idade. 

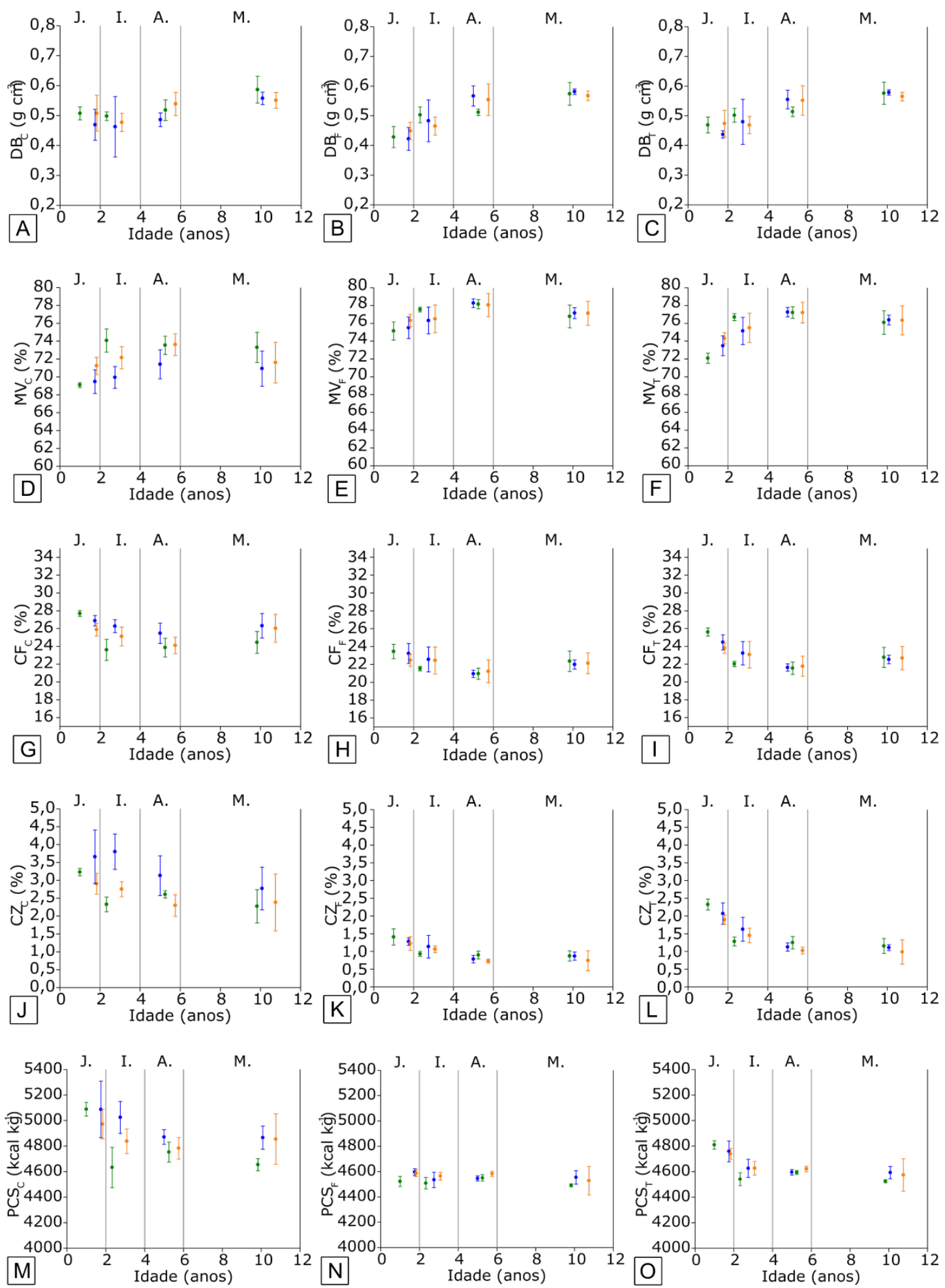

Figura 1: Média e intervalo de confiança para a densidade básica ( $D B_{C}$ dos galhos, $D B_{F}$ do fuste e $D B_{T}$ total), materiais voláteis ( $M V_{C}$ da copa, $M V_{F}$ do fuste e $M V_{T}$ total), carbono fixo (CFC da copa, $C F_{F}$ do fuste e $C F_{T}$ total), teor de cinzas ( $C Z_{C}$ da copa, $C Z_{F t}$ do fuste e $C Z_{T t}$ total) e poder calorífico superior $\left(P C S_{C}\right.$ da copa, $P C S_{F}$ do fuste e $P C S_{T}$ total) da biomassa de árvores de Acacia mearnsii sob efeito de locais de cultivo e idade dos povoamentos, no estado do Rio Grande do Sul. Em que em verde os povoamentos da região de Piratini, em azul os de Cristal, em laranja os de Encruzilhada do Sul, J. é a idade jovem, I. é a idade média inicial, A. é a idade média avançada, M. é a idade madura. 
Já os maiores intervalos de confiança para a média foram encontrados nos povoamentos da região de Cristal em idade média inicial e os menores na idade madura, não sendo observada nenhuma tendência (Figura 1A, 1B e 1C). Em trabalhos conduzidos com o gênero Eucalyptus Goulart et al. (2003) observaram que divergências na densidade podem ser decorrentes de fatores como a variabilidade genética, quando povoamentos são originados de sementes.

Quando avaliado os efeitos do local e da idade sobre a densidade básicas dos galhos foi constatado, por meio da análise de variância, efeitos independentes. Para o fuste e total esses efeitos são dependentes (Tabela 2). A densidade básica é uma característica complexa, varia entre espécies, entre árvores, radial e longitudinalmente em uma mesma árvore, ao longo da idade, com o espaçamento e local dos plantios (Mokfienski et al., 2003)

Tabela 2: Resumo da análise de variância para a densidade básica ( $D B_{C}$ dos galhos, $D B_{F}$ do fuste e $D B_{T}$ total), materiais voláteis ( $M V_{C}$ da copa, $M V_{F}$ do fuste e $M V_{T}$ total), carbono fixo ( $C F_{C}$ da copa, $C F_{F}$ do fuste e $C F_{T}$ total), teor de cinzas ( $C Z_{C}$ da copa, $C Z_{F t}$ do fuste e $C Z_{T t}$ total) e poder calorífico superior ( $P C S_{C}$ da copa, $P C S_{F}$ do fuste e $P C S_{T}$ total) da biomassa de árvores de Acacia mearnsii sob efeito de locais de cultivo e idade dos povoamentos, no estado do Rio Grande do Sul.

\begin{tabular}{|c|c|c|c|c|c|c|c|}
\hline \multirow{2}{*}{$\begin{array}{l}\text { Fonte de } \\
\text { Variação }\end{array}$} & \multirow{2}{*}{ GL } & \multicolumn{6}{|c|}{ Quadrado Médio } \\
\hline & & $D B C\left(\mathrm{~g} \mathrm{~cm}^{-3}\right)$ & $D B_{F}\left(\mathrm{~g} \mathrm{~cm}^{-3}\right)$ & $D B_{T}\left(\mathrm{~g} \mathrm{~cm}^{-3}\right)$ & $M V_{c}(\%)$ & $M V_{F}(\%)$ & $M V_{T}(\%)$ \\
\hline Local & 2 & $0,0046 *$ & $0,0003^{\text {ns }}$ & $0,0000^{\text {ns }}$ & $18,5067 *$ & $0,1398^{\mathrm{ns}}$ & $0,4653^{\text {ns }}$ \\
\hline Idade & 3 & $0,0162 *$ & $0,0473 *$ & $0,0319 *$ & $18,5414^{*}$ & $12,5975^{*}$ & $33,8267 *$ \\
\hline Local/Idade & 6 & $0,0009^{n s}$ & $0,0018 *$ & $0,0017 *$ & $4,8775^{\star}$ & $1,0751 *$ & $2,4014^{*}$ \\
\hline Erro & 35 & 0,0006 & 0,0004 & 0,0004 & 0,7902 & 0,4080 & 0,4129 \\
\hline CV & & $4,66 \%$ & $4,02 \%$ & $3,78 \%$ & $1,24 \%$ & $0,83 \%$ & $0,89 \%$ \\
\hline \multirow[t]{2}{*}{$\mathrm{R}^{2}$} & & $75,67 \%$ & $91,29 \%$ & $88,85 \%$ & $81,49 \%$ & $75,65 \%$ & $89,00 \%$ \\
\hline & & $C F_{C}(\%)$ & $C F_{F}(\%)$ & $C F_{T}(\%)$ & $C Z_{C}(\%)$ & $C Z_{F t}(\%)$ & $C Z_{T t}(\%)$ \\
\hline Local & 2 & $7,1859 *$ & $0,0624^{\mathrm{ns}}$ & $0,1081^{\mathrm{ns}}$ & $2,7995^{*}$ & $0,0090 *$ & $0,0112^{*}$ \\
\hline Idade & 3 & $12,0646^{*}$ & $8,0560 *$ & $18,4304^{*}$ & $1,4012^{*}$ & $0,1174 *$ & $0,2093 *$ \\
\hline Local/Idade & 6 & $3,2604 *$ & $0,8250 *$ & $1,6453^{*}$ & $0,2800 *$ & $0,0062 *$ & $0,0064^{*}$ \\
\hline Erro & 35 & 0,4288 & 0,3469 & 0,3123 & 0,0819 & 0,0019 & 0,0018 \\
\hline CV & & $2,57 \%$ & $2,67 \%$ & $2,41 \%$ & $10,13 \%$ & $9,80 \%$ & $30,43 \%$ \\
\hline \multirow[t]{2}{*}{$\mathrm{R}^{2}$} & & $82,51 \%$ & $70,60 \%$ & $77,04 \%$ & $79,35 \%$ & $86,89 \%$ & $91,73 \%$ \\
\hline & & $P C S_{C}\left(\mathrm{kcal} \mathrm{kg}^{-1}\right)$ & $P C S_{F}\left(\mathrm{kcal} \mathrm{kg}^{-1}\right)$ & $P C S_{T}\left(\mathrm{kcal} \mathrm{kg}^{-1}\right)$ & & & \\
\hline Local & 2 & $124.330,792 *$ & $10.166,784^{*}$ & $3.172,356^{\mathrm{ns}}$ & & & \\
\hline Idade & 3 & $176.266,140 *$ & $4.949,957 *$ & $101.960,552 *$ & & & \\
\hline Local/Idade & 6 & $35.777,436 *$ & $1.589,657^{\mathrm{ns}}$ & $5.833,199 *$ & & & \\
\hline Erro & 35 & $5.731,094$ & 797,176 & $1.210,162$ & & & \\
\hline CV & & $1,56 \%$ & $0,62 \%$ & $0,75 \%$ & & & \\
\hline $\mathrm{R}^{2}$ & & $83,17 \%$ & $61,74 \%$ & $89,14 \%$ & & & \\
\hline
\end{tabular}

Em que $C Z_{F t}=\log _{10}\left(C Z_{F}\right)$ e $C Z_{T t}=\log _{10}\left(C Z_{T}\right), C Z_{F}$ é o teor de cinzas do fuste e $C Z_{T}$ é o teor de cinzas total. $C V$ é o coeficiente de variação, $\mathrm{R}^{2}$ é o coeficiente de determinação. ${ }^{\text {ns }}$ não significativo a $5 \%$ de significância, * significativo a $5 \%$ de significância.

Os maiores valores de densidade básica dos galhos observados nos povoamentos das regiões de Encruzilhada do Sul e Piratini diferiram dos mensurados na região de Cristal. Sanquetta et al. (2013) trabalhando com povoamentos de acácia-negra em dois dos mesmos locais desse estudo (Cristal e Piratini) também encontraram diferenças entre as densidades básicas. Em relação ao fuste e ao total, os maiores valores de densidade básica foram observados nos povoamentos da região de Cristal. (Tabela 3). Silva (2002) menciona que além da idade, as variações ambientais, edáficas e genéticas podem influenciar os valores de densidade básica. Nesse caso, as diferenças provavelmente ocorreram devido a genética e as 
condições edáficas uma vez que as condições meteorológicas não apresentam grandes diferenças (Tabela 1).

Tabela 3: Resultado obtido na aplicação do teste de Tukey para a comparação das médias de densidade básica por componentes das árvores de Acacia mearnsii sob efeito de locais de cultivo e idades dos povoamentos, no estado do Rio Grande do Sul.

\begin{tabular}{|c|c|c|c|c|c|c|c|c|}
\hline \multicolumn{9}{|c|}{ Densidade básica dos galhos $\left(\mathrm{g} \mathrm{cm}^{-3}\right)$} \\
\hline Local & \multicolumn{2}{|c|}{ Média } & & & \multicolumn{2}{|c|}{ Idade } & \multicolumn{2}{|c|}{ Média } \\
\hline Cristal & 0,494 & B & & & \multicolumn{2}{|c|}{ Jovem } & 0,495 & $\mathrm{BC}$ \\
\hline Encruzilhada do Sul & 0,518 & A & & & \multicolumn{2}{|c|}{ Média Inicial } & 0,479 & $\mathrm{C}$ \\
\hline \multirow[t]{2}{*}{ Piratini } & 0,527 & A & & & \multicolumn{2}{|c|}{ Média Avançada } & 0,514 & B \\
\hline & & & & & \multicolumn{2}{|c|}{ Madura } & 0,565 & A \\
\hline Local x Idade & \multicolumn{2}{|c|}{ Jovem } & Médi & icial & \multicolumn{2}{|c|}{ Média Avançada } & \multicolumn{2}{|c|}{ Madura } \\
\hline \multicolumn{9}{|c|}{ Densidade básica do fuste $\left(\mathrm{g} \mathrm{cm}^{-3}\right)$} \\
\hline Cristal & 0,422 & $\mathrm{aC}$ & 0,483 & $a b B$ & 0,567 & $\mathrm{aA}$ & 0,581 & $\mathrm{aA}$ \\
\hline Encruzilhada do Sul & 0,449 & $\mathrm{aB}$ & 0,465 & bB & 0,554 & $\mathrm{aA}$ & 0,567 & $\mathrm{aA}$ \\
\hline Piratini & 0,423 & $\mathrm{aC}$ & 0,503 & $\mathrm{aB}$ & 0,512 & $b B$ & 0,574 & $\mathrm{aA}$ \\
\hline \multicolumn{9}{|c|}{ Densidade básica do total $\left(\mathrm{g} \mathrm{cm}^{-3}\right)$} \\
\hline Cristal & 0,454 & $\mathrm{aC}$ & 0,466 & $a b B$ & 0,551 & $\mathrm{aA}$ & 0,560 & $\mathrm{aA}$ \\
\hline Encruzilhada do Sul & 0,483 & $\mathrm{aB}$ & 0,473 & bB & 0,541 & $\mathrm{aA}$ & 0,553 & $\mathrm{aA}$ \\
\hline Piratini & 0,467 & $\mathrm{aC}$ & 0,499 & $\mathrm{aB}$ & 0,516 & $\mathrm{bB}$ & 0,584 & $\mathrm{aA}$ \\
\hline
\end{tabular}

Em que letras distintas minúsculas nas colunas e maiúsculas nas linhas diferem entre si conforme o teste de Tukey a $5 \%$ de significância.

Os povoamentos maduros apresentaram os maiores valores de densidade básica dos galhos, fuste e total. Não houve diferença na densidade básica entre os locais de cultivos em povoamentos com idade jovem e madura para o fuste e o total (Tabela 3). Isso ocorre pois há uma maior concentração de massa por volume em idades mais avançadas, corroborando com o observado por Eloy et al. (2014) para quatro espécies, entre elas a Acácia mearnsii. O que também corrobora com o resultado obtido pela análise de variância em que revelou que os efeitos do local e idade são dependentes. A dependência dos valores de densidade básica com o local de cultivo para povoamentos de acácia-negra já foi reportada por Sanquetta et al. (2013).

A densidade básica do fuste e total dos povoamentos em idade média avançada e madura foram maiores em que as demais idades, não diferindo entre si (Tabela 3). Resultados semelhante para a mesma espécie foram encontrados por Sanquetta et al. (2013) e Eloy (2015), para povoamentos com idades próximas das avaliadas. Possivelmente isso está relacionado a formação de lenho adulto na biomassa do fuste dos povoamentos mais velhos.

De acordo com Latorraca \& Albuquerque (2000) a madeira juvenil, primeiros anéis formados, apresenta menor densidade e fibras mais curtas, comparada a madeira adulta. Sette Junior et al. (2012) mencionaram que as alterações do meristema cambial e das exigências mecânico-fisiológicas, resultantes do processo de desenvolvimento das árvores, representa o aumento da espessura da parede das fibras e redução da frequência do número de vasos na formação do lenho adulto em folhosas, contribuindo para o aumento da densidade.

As condições ambientais têm influência nas atividades cambiais de formação da madeira e na sua anatomia (Oliveira et al., 2012). Como a densidade da madeira é resultado da combinação da quantidade e distribuição dos diferentes elementos anatômicos, pode-se dizer que as variações edafoclimáticas, portanto, podem afetar a densidade de forma positiva ou negativa (Carneiro et al., 2017). 


\section{Teores de materiais voláteis e carbono fixo}

Os maiores teores de materiais voláteis da copa, fuste e total foram observados nos povoamentos em idade média avançada, ou seja, os valores aumentam até a idade média avançada, entre 4 e 6 anos, tendendo a estabilizar (Figura 1D, 1E e 1F). Tendência inversa foi observada para o teor de carbono fixo, em que os maiores valores foram constatados nos povoamentos em idades jovens diminuindo até a idade média avançada e tendendo a estabilizar (Figura 1G, 1H e 1I).

Os maiores intervalos de confiança para o teor de materiais voláteis e o teor de carbono fixo da copa foram observados na idade madura, enquanto que os menores na idade jovem (Figura 1G). Para o fuste e o total, a maior variabilidade foi observada na região de Cristal e Encruzilhada do Sul, na idade média inicial, enquanto que o menor na região de Piratini na mesma idade (Figura 1H e 1I). Isso corrobora com o observado por Brand (2010), que os teores de materiais voláteis são inversamente proporcionais ao teor de carbono fixo. Para ambas as variáveis não foi observada uma tendência dos intervalos de confiança dentro de cada idade ou dentro de cada região.

Para os teores de materiais voláteis e de carbono fixo a análise de variância demonstrou que os efeitos de local e idade são dependentes (Tabela 2). Eloy (2015) avaliando o efeito da idade, de 1 a 5 anos, e espaçamento sobre as propriedades energéticas da biomassa de árvores de acácia negra também encontrou efeito significativo da idade sobre o teor de materiais voláteis e carbono fixo.

O maior teor de materiais voláteis da copa foi observado na região de Piratini em idade média inicial, o menor valor também foi constatado no mesmo local, mas em idade jovem (Tabela 4). Isso provavelmente está associado a uma maior massa de galhos na biomassa de copa, uma vez que, os galhos de acácia-negra apresentam valores mais elevados para essa variável, quando comparado as folhas (Eloy, 2015). Possivelmente o povoamento em idade média inicial da região de Piratini obteve o maior teor de materiais voláteis em consequência da maior participação de galhos na biomassa de copa, o que ocorreu em virtude do seu maior crescimento quando comparado aos demais povoamentos da mesma idade.

Tabela 4: Resultado obtido na aplicação do teste de Tukey para a comparação das médias do teor de materiais voláteis por componentes das árvores de Acacia mearnsii, sob efeito de locais de cultivo e idades dos povoamentos, no estado do Rio Grande do Sul.

\begin{tabular}{|c|c|c|c|c|c|c|c|c|}
\hline Local x Idade & \multicolumn{2}{|c|}{ Jovem } & \multicolumn{2}{|c|}{ Média Inicial } & \multicolumn{2}{|c|}{ Média Avançada } & \multicolumn{2}{|c|}{ Madura } \\
\hline \multicolumn{9}{|c|}{ Teor de materiais voláteis na copa (\%) } \\
\hline Cristal & 69,47 & $\mathrm{bC}$ & 69,94 & $\mathrm{CBC}$ & 71,41 & $\mathrm{bA}$ & 70,92 & $\mathrm{bAB}$ \\
\hline Encruzilhada do Sul & 71,23 & $\mathrm{aB}$ & 72,15 & $\mathrm{bB}$ & 73,61 & $\mathrm{aA}$ & 71,59 & $b B$ \\
\hline Piratini & 69,09 & $\mathrm{bB}$ & 74,07 & $\mathrm{aA}$ & 73,54 & $\mathrm{aA}$ & 73,30 & $\mathrm{aA}$ \\
\hline \multicolumn{9}{|c|}{ Teor de materiais voláteis no fuste (\%) } \\
\hline Cristal & 75,51 & $a b C$ & 76,31 & $\mathrm{bBC}$ & 78,27 & $\mathrm{aA}$ & 77,15 & $\mathrm{aB}$ \\
\hline Encruzilhada do Sul & 76,32 & $\mathrm{aB}$ & 76,50 & $b B$ & 78,05 & $\mathrm{aA}$ & 77,13 & $\mathrm{aB}$ \\
\hline Piratini & 75,15 & $\mathrm{bC}$ & 77,55 & $\mathrm{aAB}$ & 78,15 & $\mathrm{aA}$ & 76,78 & $\mathrm{aB}$ \\
\hline \multicolumn{9}{|c|}{ Teor de materiais voláteis total (\%) } \\
\hline Cristal & 73,48 & $\mathrm{aC}$ & 75,15 & $\mathrm{bB}$ & 77,27 & $\mathrm{aA}$ & 76,38 & $\mathrm{aA}$ \\
\hline Encruzilhada do Sul & 74,31 & $\mathrm{aC}$ & 75,49 & $b B$ & 77,21 & $\mathrm{aA}$ & 76,34 & $\mathrm{aAB}$ \\
\hline Piratini & 72,08 & $b C$ & 76,70 & $\mathrm{aAB}$ & 77,21 & $\mathrm{aA}$ & 76,09 & $\mathrm{aB}$ \\
\hline
\end{tabular}

Em que letras distintas minúsculas nas colunas e maiúsculas nas linhas diferem entre si conforme o teste de Tukey a 5\% de significância.

Em relação ao teor de materiais voláteis do fuste e do total, o maior valor foi observado no povoamento da região de Cristal em idade média avançada, em que os valores não diferiram entre os locais de cultivo (Tabela 4). O mesmo foi constatado para povoamentos em idade madura. 
Severo et al. (2006) estudando árvores de Eucalyptus citriodora constataram que as características químicas sofrem influências das variações iniciais na madeira juvenil, tendendo a valores estáveis na madeira adulta. Isso explica o fato dos maiores teores de materiais voláteis, observados na idade média avançada e madura, não apresentarem diferença significante entre os locais de cultivo.

Durante a degradação térmica da biomassa a liberação dos materiais voláteis provém das hemiceluloses (Castro, 2011) e dos extrativos (Soares et al., 2014; Vargas-Moreno et al., 2012). Assim, pode se inferir que os diferentes teores de materiais voláteis observados entre as idades dos povoamentos estão relacionados aos diferentes teores de hemicelulose e extrativos da biomassa. Dessa forma, os maiores valores na idade média avançada e madura podem ser explicados pela constatação de Neves et al. (2013), em que verificaram uma tendência de aumento dos extrativos com a idade para clones de Eucalyptus.

De modo geral, todos os teores de materiais voláteis estão entre ou abaixo do intervalo encontrado por Eloy (2015) que variaram de $74,12 \%$ a $81,67 \%$ para os componentes da biomassa de árvores de acácia-negra de um a cinco anos.

Ao contrário do observado para o teor de materiais voláteis, os maiores valores de teor de carbono fixo da copa, fuste e total foram observados nos povoamentos da região de Cristal. Em relação a idade, os maiores valores foram observados nos povoamentos jovens (Tabela 5). Assim, as tendências iniciais já discutidas corroboram com os resultados evidenciados por meio da aplicação da análise de variância e do teste de médias, revelando que os teores de carbono fixo da copa dependem do local de cultivo e da idade do povoamento.

Tabela 5: Resultado obtido na aplicação do teste de Tukey para a comparação das médias do teor de carbono fixo por componentes das árvores de Acacia mearnsii, sob efeito de locais de cultivo e idades dos povoamentos, no estado do Rio Grande do Sul.

\begin{tabular}{|c|c|c|c|c|c|c|c|c|}
\hline Local x Idade & \multicolumn{2}{|c|}{ Jovem } & \multicolumn{2}{|c|}{ Média Inicial } & \multicolumn{2}{|c|}{ Média Avançada } & \multicolumn{2}{|c|}{ Madura } \\
\hline \multicolumn{9}{|c|}{ Teor de carbono fixo da copa (\%) } \\
\hline Cristal & 26,87 & $\mathrm{aAB}$ & 26,26 & $\mathrm{aABC}$ & 25,46 & $\mathrm{aBC}$ & 26,31 & aABC \\
\hline Encruzilhada do Sul & 25,87 & $\mathrm{bA}$ & 25,10 & $\mathrm{bA}$ & 24,09 & $\mathrm{bB}$ & 26,02 & $\mathrm{aA}$ \\
\hline Piratini & 27,68 & $\mathrm{aA}$ & 23,61 & $\mathrm{CB}$ & 23,85 & $\mathrm{bB}$ & 24,43 & bB \\
\hline \multicolumn{9}{|c|}{ Teor de carbono fixo do fuste (\%) } \\
\hline Cristal & 23,22 & $a b A$ & 22,55 & $a A B$ & 20,94 & $\mathrm{aC}$ & 21,98 & $a B$ \\
\hline Encruzilhada do Sul & 22,45 & bA & 22,44 & $\mathrm{aA}$ & 21,22 & $\mathrm{aB}$ & 22,13 & $\mathrm{aA}$ \\
\hline Piratini & 23,44 & $\mathrm{aA}$ & 21,52 & $\mathrm{bBCD}$ & 20,95 & $\mathrm{aCD}$ & 22,35 & $\mathrm{aBC}$ \\
\hline \multicolumn{9}{|c|}{ Teor de carbono fixo total (\%) } \\
\hline Cristal & 24,45 & $\mathrm{bA}$ & 23,23 & $\mathrm{aB}$ & 21,61 & $\mathrm{aC}$ & 22,52 & $\mathrm{aB}$ \\
\hline Encruzilhada do Sul & 23,80 & bA & 23,06 & $\mathrm{aAB}$ & 21,77 & $\mathrm{aC}$ & 22,68 & $\mathrm{aB}$ \\
\hline Piratini & 25,60 & $\mathrm{aA}$ & 22,02 & $b B C$ & 21,54 & $\mathrm{aC}$ & 22,76 & $\mathrm{aB}$ \\
\hline
\end{tabular}

Em que letras distintas minúsculas nas colunas e maiúsculas nas linhas diferem entre si conforme o teste de Tukey a 5\% de significância.

O teor de carbono fixo dos povoamentos em idade média avançada não diferiu entre os locais de cultivo, o mesmo foi constatado para povoamentos em idade madura (Tabela 5), corroborando com o resultado obtido pela análise de variância em que revelou que os efeitos do local e idade são dependentes.

Considerando a idade de cultivo, os maiores valores de carbono fixo foram observados nos povoamentos em idade jovem (Tabela 5). Brito \& Barrichelo (1977) encontraram correlações significativas e positivas entre o teor de lignina na madeira e o teor de carbono fixo. Dessa forma, as tendências observadas para o teor de carbono fixo do fuste e para a biomassa total podem ser explicadas pelo fato de que madeira juvenil apresenta maiores teores de lignina quando comparada com a do lenho adulto (Severo et al., 2006). Os valores encontrados foram próximos dos encontrados por Eloy (2015) que variaram de 22,59 a $23,91 \%$. 


\section{Teor de Cinzas}

Para o teor de cinzas da copa, as menores médias foram observadas nos povoamentos da região de Encruzilhada do Sul e Piratini. Em relação as idades, os menores valores foram verificados nos povoamentos em idade média avançada e madura, ou seja, foi constatada uma tendência de redução nos teores de cinzas à medida que os povoamentos alcançam a maturidade (Figura 1J). O mesmo comportamento foi observado para o fuste e total (Figura $1 \mathrm{~K}$ e 1L). Esses resultados são semelhantes aos verificados por Eloy (2015) para a mesma espécie, por Moulin et al. (2015) em dois clones de E. grandis x E. urophylla com 6 e 12 meses, por Santana et al. (2012) em clone do híbrido E. grandis x E. urophylla aos 34, 48, 61, 74 e 86 meses.

Dentro de cada idade não foi observado um comportamento estável do efeito do local, ou seja, as menores médias dentro de cada idade dependem dos locais de cultivo. Já os maiores intervalos de confiança foram constatados na região de Cristal seguida de Encruzilhada do Sul, enquanto que os menores valores foram observados para a região de Piratini (Figura 1J, 1K e 1L), a mesma tendência constatada para o teor de materiais voláteis e carbono fixo. Entre as idades não foi observada uma tendência dos intervalos de confiança para o teor de cinzas.

Os menores valores do teor de cinzas da copa constatados na região de Encruzilhada do Sul e Piratini diferiram daquelas na região de Cristal. Em relação a idade, os menores valores foram observados para os povoamentos em idade média avançada e madura (Tabela 6). Isso pode ser explicado devido a menor proporção de folhas e maior dos galhos na biomassa de copa dos povoamentos em idade adulta. Eloy (2015) verificou em um experimento com acácianegra que a biomassa de folhas foi maior que a de galhos em plantios com um ano, e que, essa relação foi inversa para plantios em idades superiores. O mesmo autor também verificou que a casca e as folhas de acácia-negra apresentaram os maiores teores de cinzas quando comparado aos demais componentes.

Tabela 6: Resultado obtido na aplicação do teste de Tukey para a comparação das médias do teor de cinzas por componentes das árvores de Acacia mearnsii, sob efeito de locais de cultivo e idades dos povoamentos, no estado do Rio Grande do Sul.

\begin{tabular}{|c|c|c|c|c|c|c|c|c|}
\hline Local $x$ Idade & \multicolumn{2}{|c|}{ Jovem } & \multicolumn{2}{|c|}{ Média inicial } & \multicolumn{2}{|c|}{ Média Avançada } & \multicolumn{2}{|c|}{ Madura } \\
\hline \multicolumn{9}{|c|}{ Teor de cinzas da copa (\%) } \\
\hline Cristal & 3,66 & $\mathrm{aA}$ & 3,80 & $\mathrm{aA}$ & 3,13 & $\mathrm{aB}$ & 2,77 & $\mathrm{aB}$ \\
\hline Encruzilhada do Sul & 2,90 & $\mathrm{bA}$ & 2,75 & $\mathrm{bABC}$ & 2,30 & $\mathrm{bCD}$ & 2,38 & $a b B C D$ \\
\hline Piratini & 3,23 & $\mathrm{bA}$ & 2,33 & $\mathrm{CB}$ & 2,61 & $\mathrm{bB}$ & 2,27 & $b B$ \\
\hline \multicolumn{9}{|c|}{ Teor de cinzas do fuste transformado (\%) } \\
\hline Cristal & 0,11 & $\mathrm{aA}$ & 0,05 & $\mathrm{aA}$ & $-0,11$ & $a b B$ & $-0,06$ & $\mathrm{aB}$ \\
\hline Encruzilhada do Sul & 0,09 & $\mathrm{aA}$ & 0,03 & $a b A$ & $-0,14$ & $\mathrm{bB}$ & $-0,14$ & $\mathrm{bB}$ \\
\hline Piratini & 0,15 & $\mathrm{aA}$ & $-0,03$ & $\mathrm{bB}$ & $-0,05$ & $\mathrm{aB}$ & $-0,06$ & $\mathrm{aB}$ \\
\hline \multicolumn{9}{|c|}{ Teor de cinzas total transformado (\%) } \\
\hline Cristal & 0,31 & $a b A$ & 0,21 & $\mathrm{aB}$ & 0,05 & $a b C$ & 0,04 & $a b C$ \\
\hline Encruzilhada do Sul & 0,28 & $\mathrm{bA}$ & 0,16 & $a b B$ & 0,01 & $\mathrm{bC}$ & $-0,02$ & $\mathrm{bC}$ \\
\hline Piratini & 0,37 & $\mathrm{aA}$ & 0,11 & $\mathrm{bB}$ & 0,10 & $\mathrm{aB}$ & 0,06 & $\mathrm{aB}$ \\
\hline
\end{tabular}

Em que o teor de cinzas do fuste transformado $\left[\log _{10}\left(\mathrm{CZ}_{\mathrm{F}}\right)\right]$, teor de cinzas total transformado $\left[\log _{10}\left(\mathrm{CZ}_{\mathrm{T}}\right)\right] . \mathrm{Letras}$ distintas minúsculas nas colunas e maiúsculas nas linhas diferem entre si conforme o teste de Tukey a $5 \%$ de significância.

Em relação ao teor de cinzas do fuste e total os menores valores foram observados nos povoamentos da região de Encruzilhada do Sul, o qual diferiu das demais regiões. Para o fuste, as médias dos povoamentos em idade jovem não diferiram entre os locais de cultivo (Tabela 6). Para Andrade (2006), as cinzas correspondem aos componentes minerais presentes nos vegetais que variam entre espécies e indivíduos de uma mesma espécie. Segundo Silva et al. (1983) o conteúdo de minerais na planta é afetado pela idade fisiológica e o tamanho das 
árvores, adicionalmente de acordo com Schumacher (1992) varia também conforme o solo e as características nutricionais de cada espécie.

Considerando a idade de cultivo, os menores valores para o teor de cinzas foram observados nos povoamentos em idade média avançada e madura, não havendo diferença significante (Tabela 6). Morais et al. (2017) estudando a influências da idade de corte na composição química da madeira de clones de Eucalyptus constatou que isso ocorre em virtude de árvores mais novas requererem quantidades maiores de minerais, porque estão em uma fase crescente em que o metabolismo é acelerado, justificando assim o maior teor de cinzas.

Para a acácia-negra, Eloy (2015) verificou que os maiores teores de cinza nos componentes folhas e casca que variaram de 3,56\% a 3,96\% e 3,99\% a 4,38\%, respectivamente. Já os menores valores médios, para a madeira foram de 0,59\% a 0,73\%. Considerando que o fuste é composto de madeira e casca, e a copa por folhas e galhos, os teores de cinza observados estão próximos dos encontrados na literatura.

Os menores valores foram verificados para o fuste, seguido do total e da copa. A redução e estabilização do teor de cinzas do fuste com o aumento da idade podem estar relacionada a mobilidade dos minerais na planta (Rocha, 2011), em virtude de em cada etapa do desenvolvimento fisiológico a demanda de nutrientes ser diferente para cada componente.

\section{Poder calorífico superior}

As maiores médias para o poder calorífico superior da copa foram verificadas nos povoamentos em idade jovem (Figura 1M). Silva et al. (2017) encontraram maior poder calorífico nas folhas que nos demais componentes da acácia negra. Considerando que a biomassa de copa é composta por folhas e galhos e são encontradas em diferentes proporções ao longo da idade, pode se atribuir os maiores valores de poder calorífico superior a maior participação de folhas na biomassa de copa dos povoamentos jovens. Os valores mensurados por Eloy (2015) para as folhas e galhos (copa) de acácia negra também revelam maiores valores de poder calorífico superior no primeiro ano após o plantio. O mesmo comportamento foi observado para o total (Figura 10).

Cristal foi a região que apresentou os maiores valores médios de poder calorífico superior da copa dentro de cada idade. Para o fuste e total, não foi observado um comportamento estável do efeito do local, ou seja, as maiores ou menores médias dentro de cada idade dependem dos locais de cultivo (Figura $1 \mathrm{~N}$ e 10).

Os maiores intervalos de confiança para a copa foram constatados nos povoamentos das regiões de Cristal e Encruzilhada do Sul, nas idades jovem e madura, respectivamente. Para o fuste e para o total, os maiores intervalos de confiança foram encontrados no povoamento da região de Encruzilhada do Sul na idade madura. Enquanto que, os menores valores para a copa, fuste e total foram observados na idade média avançada e madura na região de Piratini (Figura $1 \mathrm{M}, 1 \mathrm{~N}$ e 10 ).

Para o poder calorífico superior do fuste foi observado que os efeitos de local e idade são independentes, enquanto que para a copa e total esses efeitos são dependentes (Tabela 2). Resultado semelhante foi observado por Neves et al. (2011) em que analisaram o efeito do material genético e do local de cultivo sobre o poder calorífico superior da madeira de Eucalyptus com 68 meses e constataram somente o efeito do local.

Os maiores valores para o poder calorífico superior da copa, fuste e total foram observados nos povoamentos jovens, diferiram dos demais (Tabela 7). Segundo Jara (1989), o poder calorífico superior da madeira é influenciado pela constituição química da madeira, principalmente a lignina e extrativos. A madeira juvenil apresenta maiores teores de lignina, quando comparada com a do lenho adulto (Severo et al., 2006). Isso pode ser explicado pelo fato de a árvore precisar de mais lignina em fase inicial de crescimento para manter a sustentação do fuste e copa, uma vez que, a lignina tem essa função na planta. 
Tabela 7: Resultado obtido na aplicação do teste de Tukey para a comparação das médias do poder calorífico superior por componentes das árvores de Acacia mearnsii, sob efeito de locais de cultivo e idades dos povoamentos, no estado do Rio Grande do Sul.

\begin{tabular}{|c|c|c|c|c|c|c|c|c|}
\hline \multicolumn{9}{|c|}{ Poder calorífico superior da copa (kcal kg-1) } \\
\hline Local x Idade & \multicolumn{2}{|c|}{ Jovem } & \multicolumn{2}{|c|}{ Média Inicial } & \multicolumn{2}{|c|}{ Média Avançada } & \multicolumn{2}{|c|}{ Maduro } \\
\hline Cristal & 5.087 & $\mathrm{aA}$ & 5.024 & $\mathrm{aA}$ & 4.871 & $\mathrm{aB}$ & 4.866 & $\mathrm{aB}$ \\
\hline Encruzilhada do Sul & 4.972 & $\mathrm{bA}$ & 4.838 & $\mathrm{bB}$ & 4.783 & $a b B$ & 4.854 & $\mathrm{aB}$ \\
\hline Piratini & 5.089 & $\mathrm{aA}$ & 4.633 & $\mathrm{cC}$ & 4.753 & $\mathrm{bB}$ & 4.655 & $\mathrm{bBC}$ \\
\hline \multicolumn{9}{|c|}{ Poder calorífico superior do fuste (kcal kg-1) } \\
\hline Local & \multicolumn{2}{|c|}{ Média } & & \multicolumn{3}{|c|}{ Idade } & \multicolumn{2}{|c|}{ Média } \\
\hline Cristal & 4.557 & A & & & Jovem & & 4.568 & A \\
\hline Encruzilhada do Sul & 4.565 & A & & & Média Ini & & 4.536 & $\mathrm{BC}$ \\
\hline \multirow[t]{2}{*}{ Piratini } & 4.518 & B & & & dia Avan & & 4.559 & $A B$ \\
\hline & & & & & Madur & & 4.524 & $\mathrm{C}$ \\
\hline \multicolumn{9}{|c|}{ Poder calorífico superior total (kcal kg-1) } \\
\hline Local x Idade & \multicolumn{2}{|c|}{ Jovem } & \multicolumn{2}{|c|}{ Média Inicial } & \multicolumn{2}{|c|}{ Média Avançada } & \multicolumn{2}{|c|}{ Maduro } \\
\hline Cristal & 4.759 & $\mathrm{bA}$ & 4.626 & $\mathrm{aB}$ & 4.594 & $\mathrm{aB}$ & 4.592 & $\mathrm{aB}$ \\
\hline Encruzilhada do Sul & 4.739 & $\mathrm{bA}$ & 4.627 & $\mathrm{aBC}$ & 4.620 & $\mathrm{aBCD}$ & 4.574 & $a b C D$ \\
\hline Piratini & 4.809 & $\mathrm{aA}$ & 4.541 & $\mathrm{bC}$ & 4.593 & $a B$ & 4.524 & $b C$ \\
\hline
\end{tabular}

Em que letras distintas minúsculas nas colunas e maiúsculas nas linhas diferem entre si conforme o teste de Tukey a $5 \%$ de significância.

Morais (2008) verificou que há correlação entre a lignina e a idade da árvore, com tendência de redução com o aumento da idade. De acordo com Trugilho et al. (1996) o teor da lignina tende a diminuir, pois as espécies mais jovens possuem uma maior proporção de madeira juvenil, que é mais rica em lignina do que a madeira madura.

As variações na proporção de holocelulose, lignina, extrativos e cinzas, assim como as mudanças na conformação anatômica e na densidade, influenciam as propriedades energéticas da biomassa (Furtado et al. 2012).

Resultados semelhantes foram encontrados por Eloy et al. (2014) para quatro espécies, em que o poder calorífico superior foi maior no primeiro ano após o plantio, com destaque para a Acacia mearnsii com as maiores médias. Os autores encontraram valores para a espécie que variaram de 4.442 a $4.828 \mathrm{kcal} \mathrm{kg}^{-1}$.

\section{CONCLUSÕES}

Dos fatores estudados, o efeito da idade foi mais consistente e com maior importância em relação ao efeito do local. Uma vez que os efeitos dos locais de cultivo podem ser alterados por meio de práticas de manejo, preparo de solo, adubação, entre outros, o que não ocorre para a idade.

Os povoamentos em idade jovem e média inicial se destacam por apresentarem os maiores valores de carbono fixo, poder calorífico superior e os menores valores em relação ao teor de materiais voláteis. O que os favorece em relação aos demais, quanto a qualidade de sua biomassa para a geração de energia.

No entanto, povoamentos jovens possuem uma baixa densidade básica e um baixo estoque de biomassa. Como a variação das propriedades energéticas é baixa, o estoque de biomassa é o que determinará a melhor idade para a colheita das florestas de acácia-negra. Assim, considerando qualidade e quantidade, os povoamentos mais velhos são os mais indicados para fornecer matéria prima a geração de energia.

\section{REFERÊNCIAS}

American Society for Testing Materials - ASTM. (2001). ASTM D2395-14: standard test methods for specific gravity of wood and wood-based materials (13 p.). West Conshohocken: ASTM. 
American Society for Testing Materials - ASTM. (2013a). ASTM D1762-84: standard test method for chemical analysis of wood charcoal (2 p.). West Conshohocken: ASTM.

American Society for Testing Materials - ASTM. (2013b). ASTM D5865-13: standard test method for gross calorific value of coal and coke (19 p.). West Conshohocken: ASTM.

Andrade, A. S. (2006). Qualidade da madeira, celulose e papel em Pinus taeda I.: influência da idade e classe de produtividade (Dissertação de mestrado). Setor de Ciências Agrárias, Universidade Federal do Paraná, Curitiba.

Brand, M. A. (2010). Energia de biomassa florestal. Rio de Janeiro: Interciência.

Brito, J. O., \& Barrichelo, L. (1977). Correlações entre características físicas e químicas da madeira e a produção de carvão vegetal: I. Densidade e teor de lignina da madeira de eucalipto. IPEF, 1(14), 9 20.

Carneiro, A. C. O., Vital, B. R., Frederico, P. G. U., Figueiró, C. G., Fialho, L. F., \& Silva, C. M. S. (2017). Caracterização energética das madeiras de clones de Eucalyptus cultivados em diferentes localidades. Ciência da Madeira, 8(3), 127-135. http://dx.doi.org/10.12953/2177-6830/rcm.v8n3p127135.

Castro, A. F. N. M. Efeito da idade e de material genético de Eucalyptus sp. na madeira e carvão vegetal (Dissertação de mestrado). Universidade Federal de Viçosa, Viçosa, 2011.

Costa Junior, S., Silva, D. A., Sanquetta, C. R., Behling, A., Simon, A. A., Trautenmuller, J. W., \& Ferraz, F. A. (2018). Quantificação dos estoques de biomassa de Acacia mearnsii De Wild. em diferentes idades e locais de cultivo. Scientia Forestalis, 46(120), 614-625. http://dx.doi.org/10.18671/scifor.v46n120.10.

Eloy, E. (2015). Produção e qualidade da biomassa de florestas energéticas no norte do Rio Grande do Sul, Brasil (Tese de doutorado). Setor de Ciências Agrárias, Universidade Federal do Paraná, Curitiba.

Eloy, E., Caron, B. O., Silva, D. A., Schmidt, D., Trevisan, R., Behling, A., \& Elli, E. F. (2014). Influência do espaçamento nas características energéticas de espécies arbóreas em plantios de curta rotação. Árvore, 38(3), 551-559.

Eloy, E., Silva, D. A., Caron, B. O., Trevisan, R., \& Balbinot, R. (2017). Effect of age and plant spacing on the energy properties of black wattle. Comunicata Scientiae, 8(3), 469-476. http://dx.doi.org/10.14295/CS.v8i3.1771.

Furtado, T. S., Ferreira, J. C., Brand, M. A., \& Neves, M. D. (2012). Correlation between moisture content and energy efficiency of Pinus taeda's residues at different ages. Árvore, 36(3), 577-582.

Gonçalves, J. L. M., Stape, J. L., Laclau, J. P., Smethurst, P., \& Gava, J. L. (2004). Silvicultural effects on the productivity and wood quality of eucalypt plantations. Forest Ecology and Management, 193, 45-61.

Goulart, M., Haselein, C. R., Hoppe, J. M., Farias, J. A., \& Pauleski, D. T. (2003). Massa específica básica e massa seca de madeira de Eucalyptus grandis sob o efeito do espaçamento de plantio e da posição axial no tronco. Ciência Florestal, 13(2), 167-175.

Jara, E. R. P. (1989). O poder calorífico de algumas madeiras que ocorrem no Brasil (Comunicação Técnica, No. 1797, 6 p.). São Paulo: Instituto de Pesquisas Tecnológicas.

Kumar, R., Pandey, K. K., Chandrashekar, N., \& Mohan, S. (2011). Study of age and height wise variability on calorific value and other fuel properties of Eucalyptus hybrid, Acacia auriculaeformis and Casuarina equisetifolia. Biomass and Bioenergy, 35(3), 1339-1344.

Latorraca, J. V. F., \& Albuquerque, C. E. C. (2000). Efeito do rápido crescimento sobre as propriedades da madeira. Floresta e Ambiente, 7(1), 279-291.

Mokfienski, A., Gomide, J. L., Colodete, J. L., \& Oliveira, R. C. (2003). Importância da densidade e do teor de carboidratos totais da madeira de eucalipto no desempenho da linha de fibras. In Colóquio Internacional sobre Celulose Kraft De Eucalipto (pp. 15-38). Viçosa.

Morais, P. H. D. (2008). Efeito da idade da madeira de eucalipto na sua química e polpabilidade, $e$ branqueabilidade e propriedades físicas da polpa (Dissertação de mestrado). Universidade Federal de Viçosa, Viçosa.

Morais, P. H. D., Longue Júnior, D., Colodette, J. L., Morais, E. H. C., \& Jardim, C. M. (2017). Influência da idade de colheita de Eucalyptus grandis e híbridos de Eucalyptus grandis x Eucalyptus urophylla na composição química da madeira e na pulpabilidade de kraft. Ciência Florestal, 27(1), 237-248. http://dx.doi.org/10.5902/1980509826462.

Moulin, J. C., Arantes, M. D. C., Vidaurre, G. B., Paes, J. B., \& Carneiro, A. C. O. (2015). Efeito do espaçamento, da idade e da irrigação nos componentes químicos da madeira de eucalipto. Árvore, 39(1), 199-208. http://dx.doi.org/10.1590/0100-67622015000100019. 
Neves, T. A., Protásio, T. P., Couto, A. M., Trugilho, P. F., \& Silva, V. O. (2011). VIEIRA, C. M. M. Avaliação de clones de Eucalyptus em diferentes locais visando à produção de carvão vegetal. Pesquisa Florestal Brasileira, 31(68), 319-330.

Neves, T. A., Protásio, T. P., Trugilho, P. F., Valle, M. L. A., Sousa, L. C., \& Vieira, C. M. M. (2013). Qualidade da madeira de clones de Eucalyptus em diferentes idades para a produção de bioenergia. Revista de Ciências Agrárias, 56(2), 139-148.

Oliveira, G. M. V., Mello, J. M., Trugilho, P. F., Scolforo, J. R. S., Altoé, T. F., Silva Neto, A. J., \& Oliveira, A. D. (2012). Efeito do ambiente sobre a densidade da madeira em diferentes fitofisionomias do Estado de Minas Gerais. Cerne, 18(2), 345-352. http://dx.doi.org/10.1590/S0104-7760201200020002.

Rocha, M. F. V. Influência do espaçamento e da idade na produtividade e propriedades da madeira de Eucalyptus grandis $x$ Eucalyptus camaldulensis para energia (Dissertação de mestrado). Universidade Federal de Viçosa, Viçosa, 2011.

Sanquetta, C. R., Behling, A., Corte, A. P. D., Simon, A., Pscheidt, H., Ruza, M. S., \& Mochiutti, S. (2014). Estoques de biomassa e carbono em povoamentos de acácia negra em diferentes idades no Rio Grande do Sul. Scientia Forestalis, 42(103), 361-370.

Sanquetta, C. R., Trevisan, R., Behling, A., Eloy, E., Dalla Corte, A. P., Simon, A. A., \& Silva, D. A. (2013). Variação axial da massa específica básica da Acacia mearnsii em diferentes regiões do estado do Rio Grande do Sul. Revista Biociências, 19(2), 43-52.

Santana, W. M., Calegario, N., Arantes, M. D. C., \& Trugilho, P. F. (2012). Efeito da idade e da classe diamétrica nas propriedades da madeira de Eucalyptus clonal. Cerne, 18(1), 1-8.

Schumacher, M. V. (1992). Aspectos da ciclagem de nutrientes e do microclima em talhões de Eucalyptus camaldulensis Dehnh, Eucalyptus grandis Hill ex Maiden e Eucalyptus torelliana F. Mesell (Dissertação de mestrado). Escola Superior de Agricultura "Luiz de Queiroz", Universidade de São Paulo, Piracicaba.

Sette Junior, C. R., Olivera, I. R., Tomazello Filho, M., Yamaji, F. M., \& Laclau, J. P. (2012). Efeito da idade e posição de amostragem na densidade e características anatômicas da madeira de Eucalyptus grandis. Árvore, 36(6), 1183-1190.

Severo, E. T. D., Calonego, F. W., \& Sansígolo, C. A. (2006). Composição química da madeira de Eucalyptus citriodora em função das direcções estruturais. Silva Lusitana, 1(14), 113-126. Recuperado em 21 de novembro de 2017, de http://www.scielo.mec.pt/pdf/slu/v14n1/v14n1a09.pdf

Silva, D. A., Behling, A., Sanquetta, C. R., Dalla Corte, A. P., Ruza, M. S., Pscheidt, H., \& Costa Junior, S. (2017). Potencial dendroenergético dos diferentes compartimentos de Acacia mearnsii cultivada no estado do Rio Grande do Sul. Biofix Scientific Journal, 2(2), 71-75. http://dx.doi.org/10.5380/biofix.v2i2.55777.

Silva, H. D., Poggiani, F., \& Coelho, L. C. (1983). Biomassa, concentração e conteúdo de nutrientes em cinco espécies de Eucalyptus plantadas em solos de baixa fertilidade. Boletim de Pesquisa Florestal, (6-7), 9-25.

Silva, J. C. (2002). Caracterização da madeira de Eucalyptus grandis Hill ex Maiden, de diferentes idades, visando utilização na indústria moveleira (Dissertação de mestrado). Universidade Federal do Paraná, Curitiba.

Simon, A. A. (2005). A cadeia produtiva da acácia-negra, aspectos econômicos, sociais e ambientais. In A. G. Strohschoen \& C. Rempel (Eds.), Reflorestamento e recuperação ambiental: ambiente e tecnologia: o desenvolvimento sustentável em foco (pp. 149-166). Lajeado: Univates.

Soares, V. C., Bianchi, M. L., Trugilho, P. F., Höfler, J., \& Pereira Júnior, A. (2015). Análise das propriedades da madeira e do carvão vegetal de híbridos de eucalipto em três idades. Cerne, 21(2), 191-197. http://dx.doi.org/10.1590/01047760201521021294.

Soares, V. C., Bianchi, M. L., Trugilho, P. F., Pereira Júnior, A., \& Höfler, J. (2014). Correlações entre as propriedades da madeira e do carvão vegetal de híbridos de eucalipto. Árvore, 38(3), 543-549. Recuperado em 20 de novembro de 2017, de http://udlap.redalyc.org/articulo.oa?id=48831728017

Trugilho, P. F., Lima, J. T., \& Mendes, L. M. (1996). Influência da idade nas características físico-químicas e anatômicas da madeira de Eucalyptus saligna. Cerne, 2(1), 94-111.

Vargas-Moreno, J. M., Callejón-Ferre, A. J., Pérez-Alonso, J., \& Velázquez-Martí, B. (2012). A review of the mathematical models for predicting the heating value of biomass materials. Renewable \& Sustainable Energy Reviews, 16(5), 3065-3083. http://dx.doi.org/10.1016/j.rser.2012.02.054. 
Contribuição dos Autores: SC): Conceituação, Análise Formal, Investigação, Escrita - Primeira Redação; DAS: Obtenção de Financiamento, Administração do Projeto, Recursos, Supervisão; AB e HSK: Conceituação, Análise Formal, Metodologia, Validação; AAS e AC: Curadoria de Dados, Recursos, Validação. 